\title{
The Role of Presence, Flow and Education Components in the Continuing Intention to e-Learn
}

\author{
Inma Rodríguez-Ardura \\ Internet Interdisciplinary Institute, Open University of \\ Catalonia (Universitat Oberta de Catalunya) \\ Spain
}

\begin{abstract}
This paper investigates learners' experiences in virtual education environments and the impact on their continued intention to e-learn. We study how presence and flow affect behavioral intention to continue e-learning, and analyze the role of TAM perceptions on core components of the virtual education environment. We develop an integrated conceptual model, and we test it by means of a questionnaire-based survey and registered data collected from a broad sample of learners within a virtual education environment. The results strongly support the conceptual model, suggesting that the virtual education environment's components (categorized by professor attitude and perceived didactic resource quality) play a key role in prompting learners' perceptions, attitudes and behavioral intentions.
\end{abstract}

Keywords-e-learning; professor attitude; didactic resources; presence; flow; TAM

\section{INTRODUCTION}

Digital didactic resources and teaching processes have been identified as central components of e-learning programs. Yet scholars and education institutions alike still have much to study about the connections between these two important components of online programs and the e-learners' tendency to continue using virtual education environments.

To analyze continuing intention to e-learn, TAM [1] [2] is a valid theoretical framework. However, the TAM constructs of perceived ease of use and perceived usefulness do not fully capture the range of psychological phenomena elicited by elearning. On the basis of literature in consumer behavior, reference [3] suggests that users of virtual environments interpret incoming information from affective and cognitive mechanisms. While affective processing facilitates perceptions related to utilitarian facets of the virtual environment, like TAM perceptions, cognitive processing intervenes in the emergence of senses of presence and flow states, which occur when users entirely immerse themselves in the virtual environment [3].

We further understand presence and flow as related, yet distinct facets of individual's cognitive immersion [4] in a virtual education environment. While presence will cover the spatial aspects when feeling placed in the virtual education environment, flow will refer to the state occurring when being focused on the learning activity developed in this alternative realm.

\author{
Antoni Meseguer-Artola \\ Internet Interdisciplinary Institute, Open University of \\ Catalonia (Universitat Oberta de Catalunya) \\ Spain
}

The role of presence in e-learning experiences has been pointed out by e-learning literature, which has identified it as critical in immersing individuals in teaching-learning processes [5]. By its part, flow has found to make the virtual environments' usage easier, and to lead to favorable attitudes [6] and learning performance [7].

\section{CONCEPTUAL MODEL AND HYPOTHESES}

Our integrated model of the continuing intention to e-learn includes four types of causal pathways: pathways that stem from presence research (H1-H4), pathways from Flow Theory (H5-H8), extended TAM pathways rooted in e-learning literature (H9-H13), and original TAM paths (H14-H17) - see Table I.

TABLE I.

\begin{tabular}{|l|l|l|}
\hline & $\begin{array}{c}\text { Hypothesized paths of the model and contexts of prior testing } \\
\text { Hypothesized } \\
\text { pathays }\end{array}$ & \multicolumn{1}{|c|}{ Contexts of prior testing } \\
\hline $\mathrm{H} 1(+)$ & $\mathrm{PA} \rightarrow \mathrm{P}$ & E-learning satisfaction [8] \\
\hline $\mathrm{H} 2(+)$ & $\mathrm{PDRQ} \rightarrow \mathrm{P}$ & No prior testing \\
\hline $\mathrm{H} 3(+)$ & $\mathrm{P} \rightarrow \mathrm{F}$ & E-learning attitude [9] \\
\hline $\mathrm{H} 4(+)$ & $\mathrm{P} \rightarrow \mathrm{CINT}$ & E-learning adoption [10] \\
\hline $\mathrm{H} 5(+)$ & $\mathrm{PDRQ} \rightarrow \mathrm{F}$ & E-learning adoption [11] \\
\hline $\mathrm{H6}(+)$ & $\mathrm{PEOU} \rightarrow \mathrm{F}$ & Continuing intention to e-learn [12] \\
\hline $\mathrm{H} 7(+)$ & $\mathrm{F} \rightarrow \mathrm{AP}$ & Self-reported performance [7] \\
\hline $\mathrm{H} 8(+)$ & $\mathrm{F} \rightarrow \mathrm{AU}$ & Continuing intention to e-learn [13] [14] \\
\hline $\mathrm{H} 9(+)$ & $\mathrm{PA} \rightarrow \mathrm{PDRQ}$ & Perceived quality of e-learning [15] \\
\hline $\mathrm{H} 10(+)$ & $\mathrm{PA} \rightarrow \mathrm{PEOU}$ & No prior testing \\
\hline $\mathrm{H} 11(+)$ & $\mathrm{PA} \rightarrow \mathrm{PU}$ & E-learning adoption [11] [16] \\
\hline $\mathrm{H} 12(+)$ & $\mathrm{PDRQ} \rightarrow \mathrm{PEOU}$ & E-learning adoption [11] [16] [17] \\
\hline $\mathrm{H} 13(+)$ & $\mathrm{PDRQ} \rightarrow \mathrm{PU}$ & E-learning adoption [11] [16] [17] \\
\hline $\mathrm{H} 14(+)$ & $\mathrm{PEOU} \rightarrow \mathrm{PU}$ & Continuing intention to e-learn [13] [18] [19] \\
\hline $\mathrm{H} 15(+)$ & $\mathrm{PEOU} \rightarrow \mathrm{AU}$ & Continuing intention to e-learn [13] \\
\hline $\mathrm{H} 16(+)$ & $\mathrm{PU} \rightarrow \mathrm{AU}$ & Continuing intention to e-learn [13] [18] \\
\hline $\mathrm{H} 17(+)$ & $\mathrm{AU} \rightarrow \mathrm{CINT}$ & Continuing intention to e-learn [13] [18] \\
\hline
\end{tabular}


a. PA: professor attitude; P: presence; PDRQ: perceived didactic resources quality; F: flow; CINT: continued intention to e-learn; PEOU: perceived ease of use of the e-learning environment; AP: Academic performance; AU: attitude towards using the e-learning environment; PU: perceived usefulness of the e-learning environment.

\section{METHOD}

\section{A. Data collection}

The data employed was obtained from the Universitat Oberta de Catalunya (Open University of Catalonia) in Barcelona, Spain. Data collection was carried out through a web-based survey (conducted in Spring term 2010), and registrar's office data of students' course grades (also for the Spring term 2010).

The sample frame consisted of current undergraduate and graduate students of online programs, who had already taken and passed a term at the University. A total of 2,530 usable questionnaires were obtained.

\section{B. Measurement}

Measurement items for the constructs in the survey were selected from prior research [1] [15] [19] [20] [14] [21] [2]. Items were adapted to the concrete virtual education environment of the University, and made available in the two languages used by e-learners (Spanish and Catalan). All items were answered on a 7-point Lykert-type scale, anchored between ‘strongly disagree' and ‘strongly agree'.

AP was captured by adding the final marks achieved in all courses taken by the e-learner in the term of reference. Course grades ranged from zero (unsatisfactory) to five (excellent work).

\section{RESUlTS}

Tests of the model were carried out through structural equation modeling. Model estimation was done with the maximum likelihood approach.

\section{A. Measurement model}

To assess internal reliability, the Cronbach's $\alpha$ and itemto-total correlation were computed for each construct. All values improved the minimum required bounds. To analyze the convergent validity, it was checked first that all factor loadings (associated to each construct) were above the value of 0.60 ; second that the composite reliability values were grater than 0.70; and third that the variance extracted was lower than the composite reliability values. With respect the discriminant validity of each construct, it was obtained the required condition that the average of the variance extracted was greater than the maximum shared variance and the average shared variance

\section{B. Structural model}

The absolute fit measures of the model (goodness of fit index, standardized root mean square residual, root mean square error) satisfied the required standard conditions. The incremental fit mesures (the adjusted goodness of fit index, Tucker-Lewis index and the comparative fit index) were greater than the required lower bounds. All parsimonious fit measures (parsimonious goodness of fit index, parsimonious normed fit index, and parsimonious comparative fit index) were closer to 1 . These results showed a good fit of the model.

Since all path weights were positive and significantly different from zero at 99\%, all the hypothesized pathways were supported.

\section{CONCLUDING DISCUSSION}

Our investigation fills a gap in the literature in e-learning, by connecting two critical components of online education programs (PDRQ, PA) with e-learners' behavioral intentions. Our research suggests that these two education components are relevant antecedents of P, PEOU and PU; and that PDRQ triggers F. Furthermore, it notes that PDRQ and PA indirectly elicit CINT. Another interesting result is that PA influences PEOU and, indirectly, F. These findings further shows the crucial role played by professors (along with didactic resources) in continuing intention to e-learn.

\section{References}

[1] F.D. Davis, "Perceived usefulness, perceived ease of use, and user acceptance of information technology,” MIS Quarterly, vol. 13 (3), pp. 319-340, 1989.

[2] F.D. Davis, R.P. Bagozzi, and P.R. Warshaw, "User acceptance of computer technology: a comparison of two theoretical models," Management Science, vol. 35 (8), pp. 982-1003, 1989.

[3] S. Rose, M. Clark, P. Samouel, and N. Hair, "Online customer experience in e-retailing: an empirical model of antecedents and outcomes,” Journal of Retailing, vol. 88 (2), pp. 308-322, 2012.

[4] A. Mollen and H. Wilson, "Engagement, telepresence and interactivity in online consumer experience: reconciling scholastic and managerial perspectives,” Journal of Business Research, vol. 63 (9), pp. 919-925, 2010.

[5] D.R. Garrison and J.B. Arbaugh, "Researching the community of inquiry framework: review, issues, and future directions," Internet and Higher Education, vol 10 (3), pp. 157-172, 2007.

[6] G. van Noort, H.A.M. Voorveld, and E.A. van Reijmersdal, "Interactivity in brand web sites: cognitive, affective, and behavioral responses explained by consumers' online flow experience,” Journal of Interactive Marketing, vol. 26 (4), pp. 223-234, 2012.

[7] L.A. Ho and T.H. Kuo, "How can one amplify the effect of e-learning? An examination of high-tech employees' computer attitude and flow experience," Computers in Human Behavior, vol. 26 (1), pp. 23-31, 2010.

[8] J. Kim, Y. Kwon, and D. Cho, "Investigating factors that influence social presence and learning outcomes in distance higher education," Computers \& Education, vol. 57 (2), pp. 1512-1520, 2011.

[9] P. Leong, "Role of social presence and cognitive absorption in online learning environments,” Distance Education, vol. 32 (1), pp. 5-28, 2011.

[10] R. Davis and D. Wong, "Conceptualizing and measuring the optimal experience of the elearning environment,” Decision Sciences Journal of Innovative Education, vol. 5 (1), pp. 97-126, 2007.

[11] Y.-M. Cheng, "Effects of quality antecedents on e-learning acceptance," Internet Research, vol. 22 (3), pp. 361-390, 2012.

[12] Y.-H. Tao, C.-J. Cheng, and S.-Y. Sun, "What influences college students to continue using business simulation games? The Taiwan experience,” Computers \& Education, vol. 53 (3), pp. 929-939, 2009.

[13] M.-C. Lee, "Explaining and predicting users' continuance intention toward e-learning: an extension of the expectation-confirmation model," Computers \& Education, vol. 54 (2), pp. 506-516, 2010.

[14] J.C. Roca, C.-M. Chiu, and F.J. Martínez, "Understanding e-learning continuance intention: an extension of the Technology Acceptance 
Model,” International Journal of Human-Computer Studies, vol. 64 (8, pp. 683-696, 2006.

[15] J.W. Peltier, J.A. Schibrowsky, and W. Drago, "The interdependence of the factors influencing the perceived quality of the online learning experience: a causal model,” Journal of Marketing Education, vol. 29 (2), pp. 140-153, 2007.

[16] B.-C. Lee, J.-O. Yoon, and I. Lee, "Learners' acceptance of e-learning in South Korea: theories and results," Computers \& Education, vol. 53 (4), pp. 1320-1329, 2009.

[17] I.F. Liu, M.C. Chen, Y.S. Sun, D. Wible, and C.H. Kuo, "Extending the TAM model to explore the factors that affect intention to use an online learning community,” Computers \& Education, vol. 54 (2), pp. 600-610, 2010.
[18] K.-M. Lin, "e-Learning continuance intention: moderating effects of user e-learning experience,” Computers \& Education, vol. 56 (2), pp. 515-526, 2011.

[19] Y.-S. Wang, "Assessment of learner satisfaction with asynchronous electronic learning systems,” Information \& Management, vol. 41 (1), pp. 75-86, 2003.

[20] T.P. Novak, D.L. Hoffman, and Y.F. Yung, "Measuring the customer experience in online environments: a structural modeling approach," Marketing Science, vol. 19 (1), pp. 22-42, 2000.

[21] S. Taylor and P.A. Todd, "Understanding information technology usage: a test of competing models,” Information Systems Research, vol. 6 (2), pp. 144-176, 1995.

\section{Creative Commons Attribution License 4.0} (Attribution 4.0 International, CC BY 4.0)

This article is published under the terms of the Creative Commons Attribution License 4.0

https://creativecommons.org/licenses/by/4.0/deed.en_US 